\title{
Human immunodeficiency virus type 1 envelope proteins traffic toward virion assembly sites via a TBC1D20/Rab1-regulated pathway
}

\author{
Dikla Nachmias ${ }^{1}$, Ella H Sklan ${ }^{2^{*}}$, Marcelo Ehrlich ${ }^{1 *}$ and Eran Bacharach ${ }^{1 *}$
}

\begin{abstract}
Background: The cellular activity of many factors and pathways is required to execute the complex replication cycle of the human immunodeficiency virus type 1 (HIV-1). To reveal these cellular components, several extensive RNAi screens have been performed, listing numerous 'HIV-dependency factors'. However, only a small overlap between these lists exists, calling for further evaluation of the relevance of specific factors to HIV-1 replication and for the identification of additional cellular candidates. TBC1D20, the GTPase-activating protein (GAP) of Rab1, regulates endoplasmic reticulum (ER) to Golgi trafficking, was not identified in any of these screens, and its involvement in HIV-1 replication cycle is tested here.
\end{abstract}

Findings: Excessive TBC1D20 activity perturbs the early trafficking of HIV-1 envelope protein through the secretory pathway. Overexpression of TBC1D20 hampered envelope processing and reduced its association with detergentresistant membranes, entailing a reduction in infectivity of HIV-1 virion like particles (VLPs).

Conclusions: These findings add TBC1D20 to the network of host factors regulating HIV replication cycle.

Keywords: HIV-1, envelope, assembly, TBCID20, Rab1, secretory pathway

\section{Findings}

Numerous host factors regulate, directly and indirectly, different steps of HIV-1 infection. To reveal these factors, several extensive RNAi screens have been performed, listing over a thousand proteins [1-5]. Surprisingly, there is only a small overlap between these lists, calling for further evaluation of the relevance of specific factors to HIV-1 replication [6,7]. The small GTPase Rab1 has been marked in one of these screens as a putative HIV-dependency factor [1]. Here we identified TBC1D20, a specific GAP of this Rab [8,9], as a new host factor that regulates HIV replication.

Rab1, which cycles between active GTP-bound and inactive GDP-bound forms [10], and is present as Rabla/b isoforms, regulates the early secretory pathway

\footnotetext{
*Correspondence: sklan@post.tau.ac.il; marceloe@post.tau.ac.il; eranbac@post. tau.ac.il

'Department of Cell Research and Immunology, The George S. Wise Faculty of Life Sciences, Tel Aviv University, Tel Aviv 69978, Israel

${ }^{2}$ Department of Clinical Immunology and Microbiology, Sackler School of

Medicine, Tel Aviv University, Tel Aviv 69978, Israel

Full list of author information is available at the end of the article
}

by controlling ER to Golgi traffic [11]; yet, unconventional Rab1-independent secretion pathway(s) have also been described [12-14]. TBC1D20, a Rab1-GAP, inactivates Rab1 through the stimulation of GTP hydrolysis; accordingly, TBC1D20 overproduction blocks Rab1mediated ER-to-Golgi transport $[8,9]$. The utilization of the Rab1-dependent secretory pathway by HIV-1 and the influence of TBC1D20/Rab1 axis on its infectivity remain unexplored.

The maturation and assembly of HIV-1 envelope (Env) occur along the secretory pathway. Env maturation requires post-translational modifications, including the initial acquisition of high-mannose sugar trees that occurs within the ER. Subsequent maturation steps such as the trimming of this sugar-tree, acquisition of different sugars that modify Env apparent molecular weight $(\mathrm{MW})$ and the furin-mediated cleavage of gp160 precursor to gp120 and gp41, require Env transport through posterior secretory pathway compartments [15]. Finally, targeting to specific domains of the plasma membrane is required for efficient assembly of Env into nascent 
virions $[16,17]$. Despite extensive study, the full milieu of specific factors and secretory pathways involved in these processes remains unknown. To investigate if Env maturation and trafficking are regulated by TBC1D20 and occur via Rab1-dependent pathway, we exploited the effect induced by imbalanced expression of TBC1D20 on Rab1-mediated transport, and probed for the infectivity of HIV-1 VLPs in such conditions. In previous studies, it was shown that TBC1D20 is a negative regulator of the ER-to-Golgi traffic of a temperature sensitive mutant of the envelope glycoprotein of the vesicular stomatitis virus (VSV-G) in HeLa cells $[8,9]$. To expand this finding to the present experimental system, 293T cells were co-transfected with plasmids encoding for VSV-G $(2.5 \mu \mathrm{g})$, the HIV-1 Gag-Pol $[\Delta \mathrm{R} 8.2 ;[18] 7.5 \mu \mathrm{g}]$, a retroviral vector encoding GFP [pHR'CMV-GFP [19]; $10 \mu \mathrm{g}$ ], and Myc-tagged TBC1D20 [pMyc-TBC1D20 [9]; $10 \mu \mathrm{g}$ ]. A Myc-tagged catalytically inactive form of TBC1D20 [R105A [8,9]; $10 \mu \mathrm{g}$ )], or an empty vector [pCMV-Myc (Clontech); $10 \mu \mathrm{g}$ ] served as controls. Supernatants were collected $48 \mathrm{~h}$ post transfection and equal amounts of VLPs, normalized by RT exogenous assay [20], were used to infect naïve HeLa TZMbl cells, expressing CD4, CXCR4 and CCR5 molecules [21]. Of note, TZM-bl cells carry the LTR-driven firefly luciferase as well as the $\beta$-galactosidase reporter genes to monitor HIV infection; however, we used the GFP reporter in PHR'CMV-GFP vector to quantify infection levels since this vector does not express the Tat protein, which is essential for luciferase and $\beta$-galactosidase activation in infected TZM-bl cells; and as GFP expression enables the quantification of large numbers of infected cells through fluorescence-activated cell sorting (FACS) analysis. Figure $1 \mathrm{~A}$ shows that in accord with a block to VSV-G trafficking, overexpression of TBC1D20 decreased the number of infected cells (GFP+) to 20\% of the control. To address if HIV Env is analogously regulated, a similar experiment was performed with HIV Env [JRCSF [22]; $2.5 \mu \mathrm{g}$ ] (Figure 1B). Here too, TBC1D20 overexpression decreased the infectivity of VLPs suggesting that VSV-G and HIV Env traffic through a Rab1-sensitive pathway.

To further characterize the source of this decrease, $293 \mathrm{~T}$ cells were transfected with $\Delta \mathrm{R} 8.2(1 \mu \mathrm{g})$, JRCSF $(1.5 \mu \mathrm{g})$ together with pMyc-TBC1D20, R105A or pCMV-Myc ( $3 \mu \mathrm{g}$ each). Lysates from the transfected cells and virions purified from the culture supernatants by ultracentrifugation through a $25 \%$ sucrose cushion were subjected to Western blot analysis (Figure 2). Similar capsid (CA) levels were observed in all the samples, suggesting that $\mathrm{TBC} 1 \mathrm{D} 20$ overexpression did not reduce VLPs production. In contrast, TBC1D20 overexpression greatly decreased the levels of gp160 and gp41 in VLPs (Figure 2A; 'Virion Pellets' panel): the average levels of
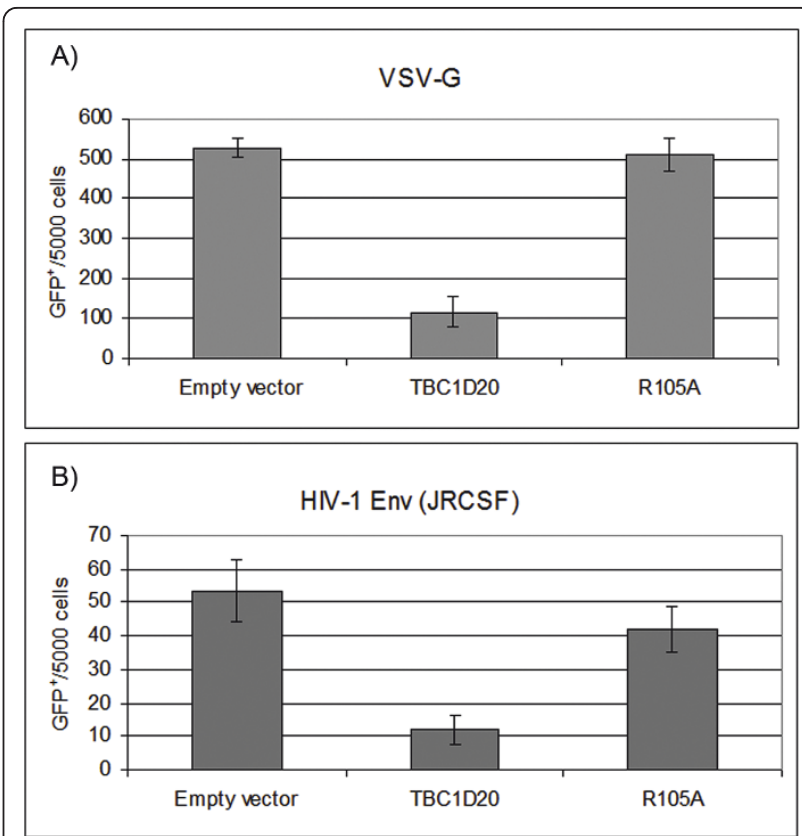

Figure 1 Overexpression of TBC1D20 decreases HIV-1 VLPs infectivity. HIV-1 VLPS, pseudotyped with either VSV-G (A) or JRCSF (B) glycoproteins, were generated in $293 \mathrm{~T}$ cells $(\sim 5 \times 106$ cells/60 mm plate), overexpressing TBC1D20, R105A, or empty vector. HeLa TZM-bl cells were infected with equal amounts of these VLPS and the number of GFP ${ }^{+}$cells per 5,000 cells was determined by FACS. The data are represented as the mean \pm the standard error of the mean (SEM, $n=3)$.

Env proteins, measured by densitometry in three independent experiments, was $18 \% \pm 7$ (gp160) and $0.8 \% \pm$ 0.5 (gp41), compared to the $100 \%$ of the empty vector control. Overexpression of R105A resulted in a smaller reduction (Figure 2A; 'Virion Pellets' panel), with average levels of $80 \% \pm 5$ (gp160) and 39\% \pm 17 (gp41). The reduction in Env virion levels observed for R105A may be explained by the fact that although catalytic inactive, it is still able to interact with other cellular proteins such as the reticulon [8]. This latter protein is localized to the ER, and evidence exist for its influence on ER-toGolgi trafficking, vesicle formation and membrane morphogenesis [23]. Thus, R105A overexpression may still affect Env levels to some extent in a Rab1-independent manner. In any case, the reduction in the virion Env levels, observed for either TBC1D20 or R105A expression, is in agreement with the decrease in VLPs infectivity (Figure 1B). TBC1D20 overexpression resulted in a faster migrating form of gp41 (Figure 2A; 'Cell Extracts' panel), likely reflecting altered glycosylation (see below). This change in migration was not evident for gp160, as expected for ER-localized protein. While TBC1D20overexpression altered the migration of gp41 in all experiments $(n=15)$, in some experiments $(n=7)$ a small reduction in gp41 level was also observed, 
A)

B)
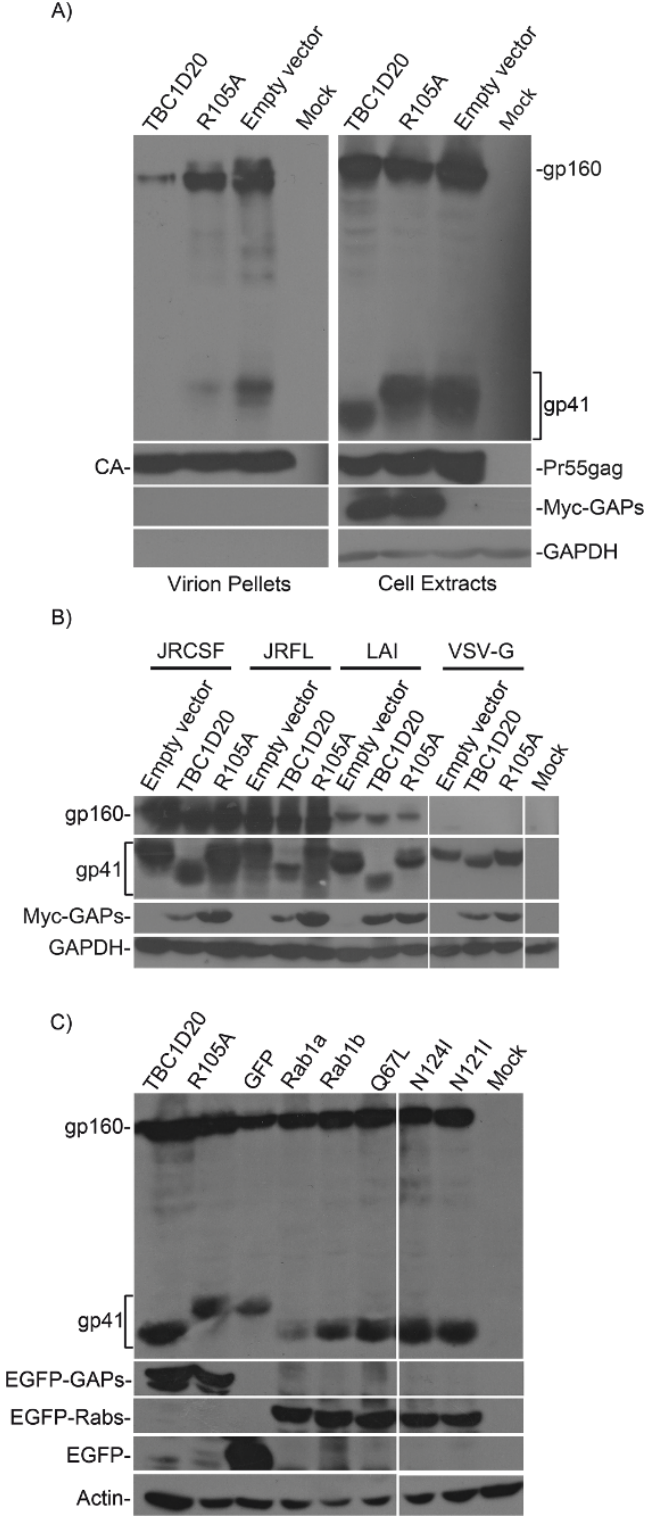

Figure 2 Overexpression of TBC1D20 alters the apparent MW of Env and decreases its incorporation into VLPs. (A) HIV-1 VLPS, pseudotyped with JRCSF envelope, were generated in 293T cells ( $\sim 2 \times 106 /$ well, 6-well plate) overexpressing the indicated GAPs (TBC1D20 or R105A) or an empty vector. Cell extracts were prepared from transfected cells and from virion pellets that were purified from the supernatants of the transfected cultures. Western blot was used to detect the expression of Env, Myc-tagged GAPs, CA and GAPDH, using monoclonal antibodies against gp41 [Chessie 8 hybridoma, [37]; Myc epitope (9E10 hybridoma); CA [183-H12-5C hybridoma, [46]] and GAPDH (Chemicon, cat. \#MAB374). (B) Identical procedure was used to monitor the effect of overexpression of the indicated GAPs on the apparent MW of gp41 (JRFL, LAI and JRCSF strains) and VSV-G; and (C) to monitor this effect on JRCSF EnV upon overexpression of the indicated Rab forms. These forms were expressed as GFP fusions [9], where the parental pEGFP-C1 plasmid (Clonetech), expressing the GFP alone, served as a negative control. Antibodies against GFP (Convance, cat. \#MMS-118R) and actin (MP Biomedicals, cat. \#69100) were used to detect protein expression. probably reflecting a reduction in gp160 cleavage (see for example the LAI Env in Figure 2B, where gp160 level was higher but gp41 level was reduced, in the TBC1D20 sample compared to the controls). Overall, these data suggest that enhanced TBC1D20 activity caused abnormal Env processing and reduced its incorporation into nascent virions, correlating with the reduced infectivity of such particles.

Because of the profound effect of TBC1D20 overexpression on gp41 migration (JRCSF strain), we expanded this analysis to the JRFL (R5 strain) and LAI (X4 strain) envelope proteins $[22,24,25]$ and to the VSV-G. TBC1D20 overexpression resulted in abnormal migration of all these proteins (Figure 2B). This result is in line with TBC1D20 effect on ER-to-Golgi trafficking of VSV-G $[8,9]$ and with the reduced infectivity of HIV-1 VLPs pseudotyped with VSV-G (Figure 1A). Overall, these results indicate the generality of TBC1D20 activity on the cellular processing of the envelope glycoproteins of these viruses. In accord with this conclusion, TBC1D20 overexpression also resulted in abnormal migration of the transforming growth factor beta receptor II (TGF $\beta$ receptor II) - a glycosylated cellular protein that traffics through the secretory pathway to the plasma membrane (data not shown).

The above effect of TBC1D20 on the migration of envelope glycoproteins is expected to reflect a lack of Rab1 activity - the target of TBC1D20. We next examined if direct modulations of Rab1 activity will similarly affect gp 41 migration. We transfected cells with the JRCSF Env and Gag-Pol proteins (as in Figure 2A) and either TBC1D20, R105A, Rab1a, Rab1b, constitutivelyactive Rab1b (Q67L) [26] or the dominant negative (DN) forms of Rab1a (N124I) or Rab1b (N121I) [11]. All of these proteins were expressed as GFP fusions [9], accordingly a GFP only negative control was used. All treatments, except for the negative controls (R105A or GFP), induced the aberrant migration of gp 41 (Figure $2 \mathrm{C}$ ). The DN activity of N124I and N121I, similar to TBC1D20 overexpression, reduces Rab1 function and thus the aberrant migration of gp41 is expected. Surprisingly, overexpression of Rab1a, Rab1b or Q67L, which enhances Rab1 activity, also resulted in abnormal gp41 migration. An explanation for this might be the observation that excesses of Rab1 activity increase ER-to-Golgi transport [27], and this too may impair proper glycosylation. Thus, a precise regulation of the Rab1/TBC1D20 axis may be necessary for proper gp 41 processing.

Sugar modifications are indicative of protein trafficking through specific compartments of the secretory pathway [28]. Since TBC1D20/Rab1 function in regulating ER-to-Golgi trafficking $[8,9,11]$ and since Env is heavily glycosylated [29], the observed aberrant migration of Env in SDS-PAGE for cells overexpressing 
TBC1D20 suggests alterations in Env glycosylation and trafficking. To study this, we performed deglycosylation sensitivity assays, as described [30]. 293T cells were transfected as described in Figure 2 and lysed; the extracts were treated with endoglycosidase $\mathrm{H}$ (EndoH), which cleaves $\mathrm{N}$-linked high-mannose oligosaccharides, found on proteins located in the ER/cis Golgi [31]. SDSPAGE-immunoblot analysis of lysates of cells expressing JRCSF Env, using anti-gp41 antibodies, yielded two main forms of Env corresponding to gp160 and gp41 that appeared smeared, suggesting multiple glycosylated forms of Env (see 'empty vector' and 'R105A' controls Figure 3A, lanes 1 and 5). To confirm that the broad distribution of Env molecules stems from glycosylation, we digested the cell lysates with Peptide:N-glycosidase F (PNGase F), which removes all types of N-linked glycosylation [32]. Indeed, this treatment resulted in the collapse of the smears to distinct bands of approximately 96 and $39 \mathrm{kDa}$; matching the net MW of these proteins

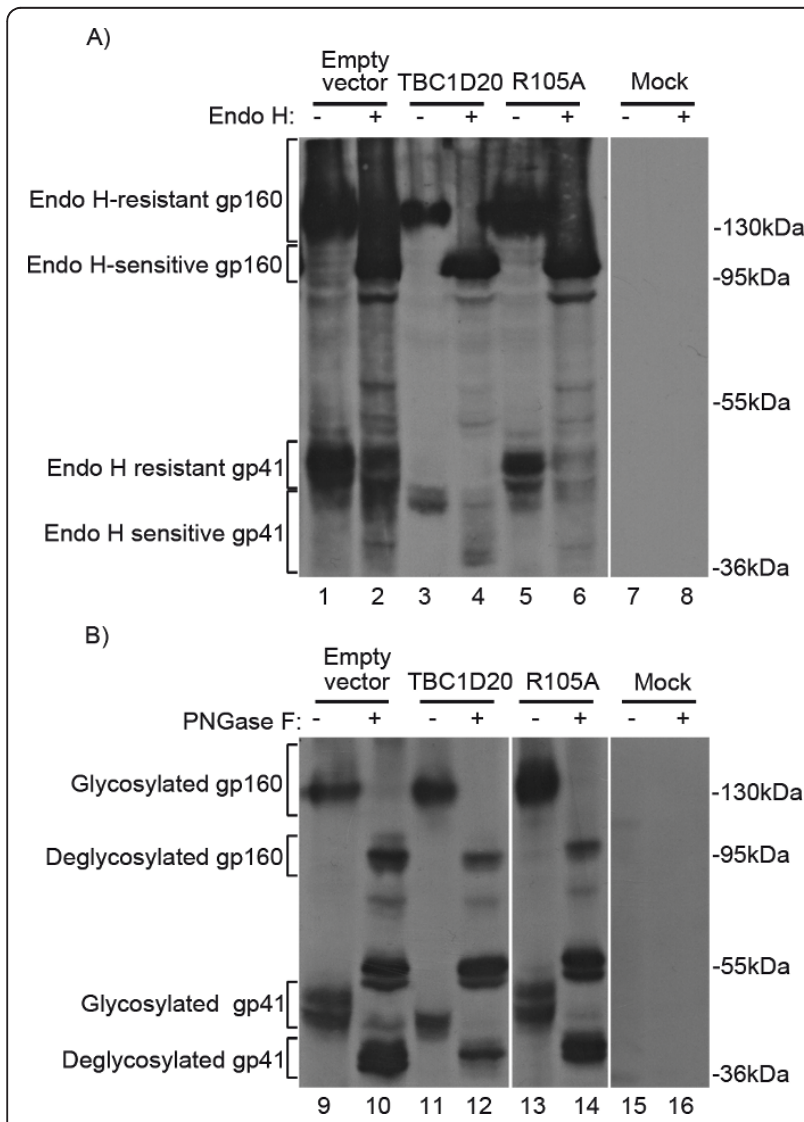

Figure 3 TBC1D20 overexpression impairs proper HIV Env glycosylation. Extracts (100 $\mu \mathrm{g}$ of total protein) of $2 \times 10^{6} 293 \mathrm{~T}$ cells expressing HIV-1 Gag-Pol and JRCSF Env proteins, together with either TBC1D20, or controls (R105A or empty vector), were treated with ('+') or without ('-') EndoH (A) or PNGase F (B). Extracts were examined by Western blot analysis using anti-gp41 monoclonal antibody, to detect gp160 and gp41. (see controls - Figure 3B, lanes 9, 10, 13 and 14). EndoH treatment resulted in a similar collapse of gp160 forms while failing to markedly alter the distribution of majority of gp41 molecules (see controls - Figure 3A, lanes 1, 2, 5 and 6; 'EndoH-resistant gp41'). These results are in accord with ER localization of gp160 as it is mainly EndoH-sensitive and support the traffic of gp41 up to the trans-Golgi network since it is both furin-cleaved and EndoH-resistant [33]. These results are also in line with previous studies that established that the kinetics of EndoH-resistance closely parallel those of Env cleavage [34]. Next, we addressed the effect of TBC1D20 on Env glycosylation. While all Env forms were equally sensitive to PNGase F (Figure 3B, lanes 11 and 12), and gp160 remained EndoH-sensitive (Figure $3 \mathrm{~A}$, lanes 3 and 4), a clear reduction in the apparent MW of gp41 was observed both prior to, and following, EndoH treatment (Figure 3A, lanes 3 and 4). Specifically, in untreated lysates a lower form of gp41 ( 41 $\mathrm{kDa}$ ) was observed; furthermore, in EndoH-treated lysates the majority of gp41 collapsed to about $39 \mathrm{kDa}$, suggesting EndoH sensitivity. These observations support the ER retention of Env upon TBC1D20 overexpression. The low but detectable level of EndoHsensitive gp41 present in TBCID20-expressing cells may indicate the premature cleavage of gp160. This may be the result of abnormal retention of furins in the ER, resulting in untimely cleavage of gp160. Alternatively, the ER localization of cleaved Env may result from its retrograde transport back into the ER. Another explanation is that this form of EndoH-sensitive gp41 may represent gp41 molecules that had normally proceeded through the Golgi yet retained highmannose oligosaccharide side chains, since it has been shown that gp120 and gp41 contain both high-mannose (EndoH-sensitive) and terminally processed (EndoH-resistant) carbohydrate chains [34]. In this case, the presence of high-mannose side chains does not necessarily indicate a pre-Golgi localization. However, even in this scenario, the fact that TBC1D20 overexpression resulted in almost a full elimination of EndoH-resistant gp41 forms (Figure 3A, compare lanes 1 and 3) suggests TBC1D20-mediated impairment of Env trafficking. Of note, the anti-gp41 Chassie antibody also detected $\sim 55 \mathrm{kDa}$ bands in PNGase F-treated extracts (Figure $3 \mathrm{~B}$ ). In principle, these bands can correspond to deglycosylated from of gp120 since Nlinked glycans comprise about $50 \%$ of the mass of gp120 [35] and as PNGase F treatment shifts gp120 MW to $\sim 60 \mathrm{kDa}$ [36]. Indeed, these bands also reacted with anti-gp120 antibody when the membrane was reprobed (data not shown). However, since the Chassie antibody does not react with gp120 (our observations and see [37]), we cannot exclude the possibility that 
the antibodies cross-reacted with a deglycosylated protein that is not related to HIV Env.

To achieve efficient assembly, Env proteins need to localize to microdomains at the plasma membrane, named detergent-resistant membranes (DRMs) [16,17]. The here-described TBC1D20-induced alterations of Env trafficking are expected to reduce its localization at these sites. To investigate this, we monitored the distribution of gp41 between DRMs and soluble fractions in cells overexpressing TBCID20, R105A (both fused to GFP), or GFP alone, using equilibrium flotation centrifugation [38]. Caveolin, expressed in 293T cells and localized to DRMs, served as a marker for DRMs-enriched fractions [16,17]. 293T cells were transfected (as described in Figure 2A, with four fold DNA amounts), $36 \mathrm{~h}$ post transfection the cultures were moved from $37^{\circ}$ $\mathrm{C}$ to $15^{\circ} \mathrm{C}$ for an additional $4 \mathrm{~h}$ to retain proteins in the ER [39]. Then, cyclohexamide $(50 \mu \mathrm{g} / \mathrm{ml})$ was added to inhibit protein synthesis, and the cultures were reincubated at $37^{\circ} \mathrm{C}$ (for $8 \mathrm{~h}$ ) to synchronize the ER exit of proteins. Subsequently, cells were extracted at $4^{\circ} \mathrm{C}$ with Triton X-100, and the lysates were separated on sucrose gradients (Figure 4A). Fractions of the gradients were analyzed by Western blotting, using anti-gp41 and anticaveolin antibodies (Figure 4B). This analysis revealed that overexpression of TBC1D20, but not controls, resulted in marked reduction in DRM-localized gp41 (Figure 4B; fractions 4-7), while the remaining gp41 was localized to soluble fractions (Figure 4B; fractions 9-12, boxed). The average ratio between gp41 levels in soluble versus detergent-resistant fractions, calculated by densitometry was approximately five times higher for TBC1D20-overexpression, compared to the controls ( $n$ $=3$, Figure 4C). These results are in line with Env localization to the earlier membrane compartments of the secretory pathway upon TBC1D20 overexpression (see Figure 3); further suggesting that TBC1D20 overexpression reduces the trafficking of Env towards the assembly sites at the plasma membrane. The residual Env levels found in virions and DRMs upon TBC1D20 overexpression (Figure 2A and 4) could result from early Env targeting to the plasma membrane, before TBC1D20 blockage and/or the outcome of residual Env trafficking through an unconventional secretion pathway, induced by ER stress [12,13].

Overall, TBC1D20 may affect virus replication cycle either directly, as in the case of the hepatitis $C$ virus where interaction of TBC1D20 with the viral protein NS5A is required for viral RNA replication $[9,40]$; or indirectly, as described here for HIV-1 and recently for herpes simplex virus [41], where TBC1D20 affects the ER-trafficking of the viral envelope glycoproteins.

To summarize, here, we showed that enhancement of TBC1D20 activity, a negative regulator of Rab1 function,

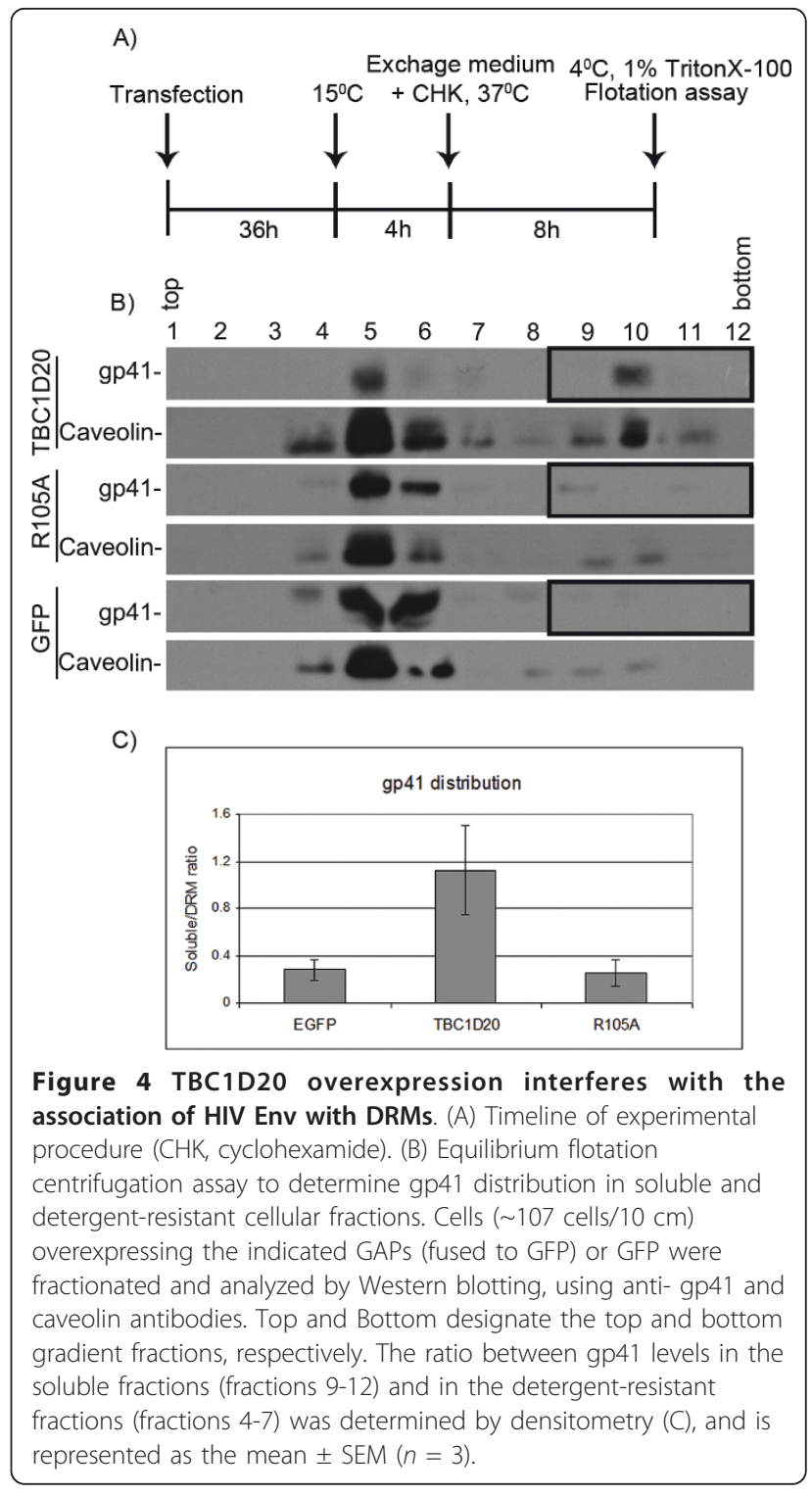

perturbs HIV-1 infectivity. This adds the TBC1D20/ Rab1 axis to other identified factors of the secretory pathway that influence HIV replication cycle, such as Rab5, 6a, 7, 9 and 11a, [1,42-45]; and places TBC1D20 in the network of host regulators of the late stages of HIV infection.

\section{Acknowledgements}

We thank Drs. Andrea Cimarelli, Jonathan Gershoni, Mia Horowitz, and Yechiel Shai for providing various reagents. The following reagents were obtained through the AIDS Research and Reference Reagent Program, Division of AIDS, NIAID, NIH: Chessie 8 hybridoma from Dr. George Lewis and the HIV-1 p24 Hybridoma (183-H12-5C) from Dr. Bruce Chesebro. This work was supported in part by the Israel Science Foundation (grant 169/09); the Ela Kodesz Institute for Research on Cancer Development and

Prevention; the Jakov, Marianna and Jorge Saia Scholarship Fund for HIV and Parkinson Diseases Research; and the Tel-Aviv University Recanati research fund. 


\section{Author details}

'Department of Cell Research and Immunology, The George S. Wise Faculty of Life Sciences, Tel Aviv University, Tel Aviv 69978, Israel. ²Department of Clinical Immunology and Microbiology, Sackler School of Medicine, Tel Aviv University, Tel Aviv 69978, Israel.

\section{Authors' contributions}

DN participated in the design of the study, performed the experiments and wrote the manuscript. EHS, ME and EB conceived of the study, participated in the design of the study, and helped to draft and edit the manuscript. All authors read and approved the final manuscript.

\section{Competing interests}

The authors declare that they have no competing interests.

Received: 18 October 2011 Accepted: 19 January 2012

Published: 19 January 2012

\section{References}

1. Brass AL, Dykxhoorn DM, Benita Y, Yan N, Engelman A, Xavier RJ, Lieberman J, Elledge SJ: Identification of host proteins required for HIV infection through a functional genomic screen. Science 2008, 319:921-926.

2. Konig R, Zhou Y, Elleder D, Diamond TL, Bonamy GM, Irelan JT, Chiang CY, Tu BP, De Jesus PD, Lilley CE, et al: Global analysis of host-pathogen interactions that regulate early-stage HIV-1 replication. Cell 2008, 135:49-60.

3. Rato S, Maia S, Brito PM, Resende L, Pereira CF, Moita C, Freitas RP, MonizPereira J, Hacohen N, Moita LF, Goncalves J: Novel HIV-1 knockdown targets identified by an enriched kinases/phosphatases shRNA library using a long-term iterative screen in Jurkat T-cells. PLoS One 5:e9276.

4. Yeung $M L$, Houzet $L$, Yedavalli VS, Jeang $K T$ : A genome-wide short hairpin RNA screening of jurkat T-cells for human proteins contributing to productive HIV-1 replication. J Biol Chem 2009, 284:19463-19473.

5. Zhou H, Xu M, Huang Q, Gates AT, Zhang XD, Castle JC, Stec E, Ferrer M, Strulovici B, Hazuda DJ, Espeseth AS: Genome-scale RNAi screen for host factors required for HIV replication. Cell Host Microbe 2008, 4:495-504.

6. Bushman FD, Malani N, Fernandes J, D'Orso I, Cagney G, Diamond TL, Zhou H, Hazuda DJ, Espeseth AS, Konig R, et al: Host cell factors in HIV replication: meta-analysis of genome-wide studies. PLoS Pathog 2009, 5 : e1000437.

7. Goff SP: Knockdown screens to knockout HIV-1. Cell 2008, 135:417-420.

8. Haas AK, Yoshimura S, Stephens DJ, Preisinger C, Fuchs E, Barr FA: Analysis of GTPase-activating proteins: Rab1 and Rab43 are key Rabs required to maintain a functional Golgi complex in human cells. J Cell Sci 2007, 120:2997-3010.

9. Sklan EH, Serrano RL, Einav S, Pfeffer SR, Lambright DG, Glenn JS: TBC1D20 is a Rab1 GTPase-activating protein that mediates hepatitis $C$ virus replication. J Biol Chem 2007, 282:36354-36361.

10. Pfeffer S, Aivazian D: Targeting Rab GTPases to distinct membrane compartments. Nat Rev Mol Cell Biol 2004, 5:886-896.

11. Tisdale EJ, Bourne JR, Khosravi-Far R, Der CJ, Balch WE: GTP-binding mutants of rab1 and rab2 are potent inhibitors of vesicular transport from the endoplasmic reticulum to the Golgi complex. J Cell Biol 1992, 119:749-761.

12. Gee HY, Noh SH, Tang BL, Kim KH, Lee MG: Rescue of DeltaF508-CFTR Trafficking via a GRASP-Dependent Unconventional Secretion Pathway. Cell 146:746-760

13. Wu G, Zhao G, He Y: Distinct pathways for the trafficking of angiotensin II and adrenergic receptors from the endoplasmic reticulum to the cell surface: Rab1-independent transport of a $\mathrm{G}$ protein-coupled receptor. J Biol Chem 2003, 278:47062-47069.

14. Yoo JS, Moyer BD, Bannykh S, Yoo HM, Riordan JR, Balch WE: Nonconventional trafficking of the cystic fibrosis transmembrane conductance regulator through the early secretory pathway. J Biol Chem 2002, 277:11401-11409

15. Swanstrom R, Wills JW: Synthesis, assembly, and processing of viral proteins. In Retroviruses. Edited by: Coffin JM, Hughes SH, Varmus HE. Cold Spring Harbor, N.Y.: Cold Spring Harbor Laboratory Press; 1997:263-334.

16. Ono A, Freed EO: Plasma membrane rafts play a critical role in HIV-1 assembly and release. Proc Natl Acad Sci USA 2001, 98:13925-13930.
17. Yang P, Ai LS, Huang SC, Li HF, Chan WE, Chang CW, Ko CY, Chen SS: The cytoplasmic domain of human immunodeficiency virus type 1 transmembrane protein gp41 harbors lipid raft association determinants. J Virol 84:59-75.

18. Naldini L, Blomer U, Gallay P, Ory D, Mulligan R, Gage FH, Verma IM, Trono D: In vivo gene delivery and stable transduction of nondividing cells by a lentiviral vector. Science 1996, 272:263-267.

19. Miyoshi H, Takahashi M, Gage FH, Verma IM: Stable and efficient gene transfer into the retina using an HIV-based lentiviral vector. Proc Natl Acad Sci USA 1997, 94:10319-10323.

20. Telesnitsky A, Blain S, Goff SP: Assays for retroviral reverse transcriptase. Methods Enzymol 1995, 262:347-362.

21. Platt EJ, Wehrly K, Kuhmann SE, Chesebro B, Kabat D: Effects of CCR5 and CD4 cell surface concentrations on infections by macrophagetropic isolates of human immunodeficiency virus type 1. J Virol 1998, 72:2855-2864.

22. Koyanagi Y, Miles S, Mitsuyasu RT, Merrill JE, Vinters HV, Chen IS: Dual infection of the central nervous system by AIDS viruses with distinct cellular tropisms. Science 1987, 236:819-822.

23. Yang YS, Strittmatter SM: The reticulons: a family of proteins with diverse functions. Genome Biol 2007, 8:234.

24. Munk C, Wei G, Yang OO, Waring AJ, Wang W, Hong T, Lehrer RI, Landau NR, Cole AM: The theta-defensin, retrocyclin, inhibits HIV-1 entry. AIDS Res Hum Retroviruses 2003, 19:875-881.

25. Peden $\mathrm{K}$, Emerman M, Montagnier L: Changes in growth properties on passage in tissue culture of viruses derived from infectious molecular clones of HIV-1LAI, HIV-1MAL, and HIV-1ELI. Virology 1991, 185:661-672.

26. Wilson AL, Sheridan KM, Erdman RA, Maltese WA: Prenylation of a Rab1B mutant with altered GTPase activity is impaired in cell-free systems but not in intact mammalian cells. Biochem J 1996, 318(Pt 3):1007-1014.

27. Cooper AA, Gitler AD, Cashikar A, Haynes CM, Hill KJ, Bhullar B, Liu K, Xu K, Strathearn KE, Liu F, et al: Alpha-synuclein blocks ER-Golgi traffic and Rab1 rescues neuron loss in Parkinson's models. Science 2006, 313:324-328.

28. Helenius A, Aebi M: Intracellular functions of N-linked glycans. Science 2001, 291:2364-2369

29. Mizuochi T, Matthews TJ, Kato M, Hamako J, Titani K, Solomon J, Feizi T: Diversity of oligosaccharide structures on the envelope glycoprotein gp 120 of human immunodeficiency virus 1 from the lymphoblastoid cell line H9. Presence of complex-type oligosaccharides with bisecting Nacetylglucosamine residues. J Biol Chem 1990, 265:8519-8524.

30. Ron I, Horowitz M: ER retention and degradation as the molecular basis underlying Gaucher disease heterogeneity. Hum Mol Genet 2005, 14:2387-2398.

31. Trimble RB, Maley F: Optimizing hydrolysis of N-linked high-mannose oligosaccharides by endo-beta-N-acetylglucosaminidase $\mathrm{H}$. Anal Biochem 1984, 141:515-522.

32. Plummer TH Jr, Elder JH, Alexander S, Phelan AW, Tarentino AL: Demonstration of peptide:N-glycosidase $\mathrm{F}$ activity in endo-beta- $\mathrm{N}$ acetylglucosaminidase F preparations. J Biol Chem 1984, 259:10700-10704.

33. Molloy SS, Thomas L, VanSlyke JK, Stenberg PE, Thomas G: Intracellular trafficking and activation of the furin proprotein convertase: localization to the TGN and recycling from the cell surface. EMBO J 1994, 13:18-33.

34. Earl PL, Moss B, Doms RW: Folding, interaction with GRP78-BiP, assembly, and transport of the human immunodeficiency virus type 1 envelope protein. J Virol 1991, 65:2047-2055.

35. Leonard CK, Spellman MW, Riddle L, Harris RJ, Thomas JN, Gregory TJ: Assignment of intrachain disulfide bonds and characterization of potential glycosylation sites of the type 1 recombinant human immunodeficiency virus envelope glycoprotein (gp120) expressed in Chinese hamster ovary cells. J Biol Chem 1990, 265:10373-10382.

36. Fenouillet $\mathrm{E}$, Gluckman JC, Bahraoui E: Role of N-linked glycans of envelope glycoproteins in infectivity of human immunodeficiency virus type 1. J Virol 1990, 64:2841-2848.

37. Abacioglu YH, Fouts TR, Laman JD, Claassen E, Pincus SH, Moore JP, Roby CA, Kamin-Lewis R, Lewis GK: Epitope mapping and topology of baculovirus-expressed HIV-1 gp160 determined with a panel of murine monoclonal antibodies. AIDS Res Hum Retroviruses 1994, 10:371-381.

38. Chan WE, Lin HH, Chen SS: Wild-type-like viral replication potential of human immunodeficiency virus type 1 envelope mutants lacking palmitoylation signals. J Virol 2005, 79:8374-8387. 
39. Hauri HP, Schweizer A: The endoplasmic reticulum-Golgi intermediate compartment. Curr Opin Cell Biol 1992, 4:600-608.

40. Sklan EH, Staschke K, Oakes TM, Elazar M, Winters M, Aroeti B, Danieli T, Glenn JS: A Rab-GAP TBC domain protein binds hepatitis C virus NS5A and mediates viral replication. J Virol 2007, 81:11096-11105.

41. Zenner HL, Yoshimura S, Barr FA, Crump CM: Analysis of Rab GTPaseActivating Proteins Indicates that Rab1a/b and Rab43 Are Important for Herpes Simplex Virus 1 Secondary Envelopment. J Virol 85:8012-8021.

42. Chu H, Wang JJ, Spearman P: HIV Interactions with Host Cell Proteins. In Current Topics in Microbiology and Immunology. Volume 339. Edited by: Spearman P. Freed EO: Springer; 2009:78-80.

43. Murray JL, Mavrakis M, McDonald NJ, Yilla M, Sheng J, Bellini WJ, Zhao L, Le Doux JM, Shaw MW, Luo CC, et al: Rab9 GTPase is required for replication of human immunodeficiency virus type 1 , filoviruses, and measles virus. J Virol 2005, 79:11742-11751.

44. Nydegger S, Foti M, Derdowski A, Spearman P, Thali M: HIV-1 egress is gated through late endosomal membranes. Traffic 2003, 4:902-910.

45. Vidricaire G, Tremblay MJ: Rab5 and Rab7, but not ARF6, govern the early events of HIV-1 infection in polarized human placental cells. J Immunol 2005, 175:6517-6530.

46. Chesebro B, Wehrly K, Nishio J, Perryman S: Macrophage-tropic human immunodeficiency virus isolates from different patients exhibit unusual V3 envelope sequence homogeneity in comparison with T-cell-tropic isolates: definition of critical amino acids involved in cell tropism. J Virol 1992, 66:6547-6554.

doi:10.1186/1742-4690-9-7

Cite this article as: Nachmias et al:: Human immunodeficiency virus type 1 envelope proteins traffic toward virion assembly sites via a TBC1D20/ Rab1-regulated pathway. Retrovirology 2012 9:7.

\section{Submit your next manuscript to BioMed Central} and take full advantage of:

- Convenient online submission

- Thorough peer review

- No space constraints or color figure charges

- Immediate publication on acceptance

- Inclusion in PubMed, CAS, Scopus and Google Scholar

- Research which is freely available for redistribution

Submit your manuscript at www.biomedcentral.com/submit
C Biomed Central 